\title{
Removal of microcystins by PAC/UF
}

\author{
Margarida Campinas ${ }^{\mathrm{a}, *}$, Maria João Rosa ${ }^{\mathrm{b}}$ \\ a University of Algarve, Gambelas Campus, 8005-139 Faro, Portugal \\ b Urban Water Division, Department of Hydraulics and Environment, LNEC - National Civil Engineering Laboratory, Av. Brasil, 101, 1700-066 Lisboa, Portugal
}

\section{A R T I C L E I N F O}

\section{Article history:}

Received 18 April 2009

Received in revised form 7 November 2009

Accepted 10 November 2009

\section{Keywords:}

PAC/UF

Microcystins

NOM

\begin{abstract}
A B S T R A C T
The removal of microcystins (MC) by powdered activated carbon adsorption/ultrafiltration (PAC/UF) was investigated, focusing on PAC dose and addition mode, MC initial concentration (expressed as MC-LReq) and on the impact of background natural organic matter (NOM), assessed through model compounds (a mixture of tannic and humic acids) and Microcystis aeruginosa culture. Constant flow experiments were performed with a hydrophilic UF hollow-fibre membrane and a mesoporous fine-powdered activated carbon. In the absence of background NOM, PAC/UF with $10 \mathrm{mg} / \mathrm{LPAC}$ and up to $20 \mu \mathrm{g} / \mathrm{L}$ MC-LR eq feed concentration achieved 93-98\% MC removal and a cycle-averaged permeate concentration below the drinking water guideline-value adopted by the World Health Organisation (WHO) for microcystin-LR variant. Single-pulse PAC dosing in the beginning of the UF-cycle allowed slightly lower MC concentration in the permeate compared to the multi-pulse PAC addition whereas no differences were found in terms of transmembrane pressure. Hydraulic retention time of 34 and 55 min resulted in similar permeate quality. NOM type and concentration and MC initial concentration determined the PAC dose to be used. While $10 \mathrm{mg} / \mathrm{L}$ PAC effectively controlled ca. $5 \mu \mathrm{g} / \mathrm{L}$ MC-LR eq in a model water with $2.5 \mathrm{mg} / \mathrm{L} \mathrm{NOM}$ or with $M$. aeruginosa culture (cells and algogenic organic matter) $15 \mathrm{mg} / \mathrm{L}$ PAC were unable to achieve the WHO quality with a water containing higher concentrations of NOM ( $5 \mathrm{mg} / \mathrm{L})$ and microcystins ( $c a .20 \mu \mathrm{g} / \mathrm{L} \mathrm{MC}-\mathrm{LR}_{\mathrm{eq}}$ ).
\end{abstract}

(c) 2009 Elsevier B.V. All rights reserved.

\section{Introduction}

Cyanotoxins are detrimental to drinking water due to their human and animal health hazard effects. They are produced as secondary metabolites of cyanobacteria and the hepatotoxic and tumour-promoter microcystins are among the most commonly occurring cyanotoxins in surface water reservoirs used for water supply. Microcystins (MC) are cyclic heptapeptides that share a general structure containing five fixed amino acids and two variable L-amino acids. They are relatively hydrophobic compounds, neutral or slightly negative at $\mathrm{pH}$ 6-9 and with a molar mass varying between 900 and $1100 \mathrm{Da}$ [1]. The World Health Organisation (WHO) adopted a provisional drinking water guideline-value of $1.0 \mu \mathrm{g} / \mathrm{L}$ for microcystin-LR (MC-LR), one of the most frequent and toxic microcystin variants.

Microcystins may occur within the cells (cell-bound or intracellular) or be released to water (extracellular or dissolved) due to cell ageing and/or induced cell lysis. Unlike cell-bound MC, dissolved microcystins are not effectively removed by conventional clarifica-

\footnotetext{
* Corresponding author. Permanent address: Urban Water Division, Department of Hydraulics and Environment, LNEC - National Civil Engineering Laboratory, Av. Brasil, 101, 1700-066 Lisboa, Portugal. Tel.: +351 218443617 fax: +351 218443032.

E-mail addresses: mgd.campinas@gmail.com (M. Campinas), mjrosa@lnec.pt (M.J. Rosa).
}

tion through coagulation/flocculation, sedimentation and filtration [2-4]. Due to their cyclic nature, microcystins are extremely stable across a wide range of $\mathrm{pH}$ and temperature although they have been shown to degrade with strong oxidants, like ozone or high doses of chlorine [5-7]. However, at the usual doses for drinking water treatment these oxidants do not completely oxidise the compounds whereas at high doses restrictions may arise due to the formation of trihalomethanes $[7,8]$ or bromate (when ozone is applied to bromide-rich waters) $[7,9,10]$. In addition, the rate of intracellular cyanotoxin release to water by the oxidant-damaged cells may exceed its degradation, yielding a net increase in the dissolved toxin. The overall efficiency of the toxin oxidation depends on the oxidant type and dose, $\mathrm{pH}$, alkalinity and natural organic matter (NOM) [11-13].

Promising technologies for dissolved MC control are membrane pressure-driven processes, e.g. nanofiltration (NF) or the hybrid process of powdered activated carbon adsorption/ultrafiltration (PAC/UF), since they act as physical barriers and do not form by-products. NF is very efficient in the removal of cyanotoxins, with rejections above 97-99\% for microcystins (feed concentration $16-150 \mu \mathrm{g} / \mathrm{L}$ MC-LR eq $[14,15]$ or $1.2-9.4 \mu \mathrm{g} / \mathrm{L} \mathrm{MC}$, where MC stands for the microcystin variants -LR, -RR, -YR and -LA [16]), regardless of the variations in the feed water quality. However, NF permeate fluxes were significantly impacted by background organics (NOM and microcystins) and especially inorganics ( $\mathrm{pH}$ and calcium) $[14,15]$. 
PAC/UF joins the adsorption capacity of PAC with the UF membrane ability to retain microorganisms and particles (including PAC particles), therefore allowing the removal of low molar mass compounds which could not be removed by the UF membrane itself (large pore size). PAC/UF is a low-pressure ( $<1$ bar) process, and as so has a relatively low operating cost. It has a high disinfection capacity (for bacteria and also Crypstosporidium oocysts, Giardia cysts and viruses) and allows a simple and effective membrane cleaning by backwashing. Furthermore, in a previous study with the PAC/UF system used in the present work [17] PAC neither promoted nor controlled the membrane reversible fouling by humic acids and algogenic organic matter (AOM) but it controlled the irreversible fouling caused by tannic acid and enhanced the NOM removal with significant advantages in terms, respectively, of membrane chemical cleaning and disinfection by-products control.

Despite its special aptitude, to our knowledge, there is only one recently published study on PAC/UF for the removal of cyanotoxins from drinking water. With a PAC (micro/mesoporous) dose of $5 \mathrm{mg} / \mathrm{L}, 4 \mathrm{~h}$ contact time and a MC-LR feed concentration of $50 \mu \mathrm{g} / \mathrm{L}$, Lee and Walker [18] reached a 98-99\% MC-LR removal by PAC/UF in the absence of background aqueous NOM and a 78-90\% removal in the presence of $5 \mathrm{mg} / \mathrm{L}$ of fulvic acid. These authors used cellulose acetate (20 kDa cut-off) and polyethersulphone (5 kDa and $20 \mathrm{kDa}$ ) flat-sheet membranes, operated in a batch recirculating mode (the UF permeate and concentrate both recirculated to the feed tank), operating conditions distant from those used in fullscale applications. Much of the previous PAC/UF research addressed the optimisation of the operating parameters through the application of mathematical models [19-26]. PAC/UF performance has shown to depend on the backwashing frequency, reactor size and configuration, filtration mode and PAC dosing procedure. PAC and therefore PAC/UF performance also depends on NOM concentration and characteristics.

Given the current knowledge on this technology for this environmental health application, the aim of this study is to investigate PAC/UF performance for the removal of microcystins from drinking water, including the assessment of the key-operating conditions and the impact of water background NOM. Two MC feed concentrations, and different PAC doses, PAC dosing procedures and hydraulic retention times are studied, as well as the effect of NOM competition (of different nature and concentration). Experimental conditions close to full-scale applications are used, namely a hollow-fibre cellulose acetate membrane $(100 \mathrm{kDa})$ and filtration cycles at constant permeate flow with membrane backwashing/cleaning in between.

\section{Experimental}

\subsection{Microcystins}

The microcystins used in the present study were extracted from Microcystis aeruginosa laboratory grown cultures (Pasteur Culture Collection - PCC 7820) in modified BG11 medium [27] (modification consisted on replacing iron and ammonia citrate by iron sulphate), at $23-24^{\circ} \mathrm{C}$, with a light regimen of $12 \mathrm{~h}$ fluorescent light $/ 12 \mathrm{~h}$ dark. The extraction followed Meriluoto and Spoof's procedure [28]. Once harvested, the cultures were centrifuged $(6000 \times g, 10 \mathrm{~min})$, the supernatant was discarded and the pellet was freeze-thawed twice. Microcystins were extracted in $75 \%$ aqueous methanol during an $18 \mathrm{~h}$ minimum period at $4{ }^{\circ} \mathrm{C}$, the methanolic extract was centrifuged twice $(10,000 \times \mathrm{g}, 10 \mathrm{~min})$ and the pellet was discarded. The MC stock solution was filtered through $1.2 \mu \mathrm{m}$ glass filters (Whatman, GF-C) and kept in the freezer until use. Prior to MC solutions preparation, the MC stock concentration was determined by high-performance liquid chromatography with photodiode-array detection (HPLC-PDA), the necessary volume was rotary evaporated and the dry extract was dissolved in deionised water. The microcystin variants detected by HPLC-PDA were MC-LR (corresponding to $c a$. 75\% of the overall concentration), -LY, -LW and -LF and the overall concentration was always quantified in MC-LR equivalent concentration $(\mu \mathrm{g} / \mathrm{L}$ MC-LReq).

\subsection{Model solutions}

The experiments were performed with two MC feed concentrations, ca. 5 and $20 \mu \mathrm{g} / \mathrm{L}$ MC-LR eq. The set of trials performed to assess the NOM effect on MC removal by PAC/UF used $M$. aeruginosa culture (cells and $\mathrm{AOM}$ ) and a mixture of two NOM model compounds, Aldrich humic acids (purified according to Hong and Elimelech's procedure described in [29]) and tannic acid (Sigma Chemicals, with no further purification), in two different concentrations, i.e. $2.5 \mathrm{mg} / \mathrm{L}$ NOM ( $1 \mathrm{mg} / \mathrm{L}$ humic acids and $1.5 \mathrm{mg} / \mathrm{L}$ tannic acid) and $5 \mathrm{mg} / \mathrm{L}$ NOM $(2.5 \mathrm{mg} / \mathrm{L}$ each). Aldrich humic acids were selected as a representative of fairly hydrophobic, high molar mass NOM $[15,29,30]$ and tannic acid as a representative of relatively hydrophilic NOM with a molar mass of $c a .1700 \mathrm{Da}$ [29,31]. A background electrolyte $2.5 \mathrm{mM}$ ionic strength (1 mM ionic strength from $\mathrm{KCl}$ and $1.5 \mathrm{mM}$ ionic strength from $\mathrm{CaCl}_{2}$ ) and pH 7.0 \pm 0.3 (adjusted by $\mathrm{KOH}$ and $\mathrm{H}_{2} \mathrm{SO}_{4}$ addition) was used in all PAC/UF experiments except on those performed with $M$. aeruginosa culture since salts were already present on the cyanobacterial growth medium. In such cases, to avoid cyanobacterial cell lysis due to osmotic shock, deionised water was first amended with $\mathrm{KCl}$ to reach a final conductivity of $260-300 \mu \mathrm{S} / \mathrm{cm}$ and it was afterwards spiked with the volume of $M$. aeruginosa culture necessary to obtain the final chlorophyll-a (chl-a) concentration of ca. $20 \mu \mathrm{g} / \mathrm{L}$.

\section{3. $P A C$}

Commercially available PAC (Norit SA-UF) was used in PAC/UF experiments. PAC doses between 5 and $15 \mathrm{mg} / \mathrm{L}$ were tested. This PAC has a BET surface area of $1112 \mathrm{~m}^{2} / \mathrm{g}$, a mesopore surface area of $379 \mathrm{~m}^{2} / \mathrm{g}$, a micropore surface area of $733 \mathrm{~m}^{2} / \mathrm{g}$ and a large pore size distribution ( $38 \%$ of primary microporous volume; $22 \%$ of secondary microporous volume and $40 \%$ of mesoporous volume) [22], which is important to adsorb microcystins in the presence of NOM. Moreover, the low diameter of the PAC particles ( $6 \mu \mathrm{m}$ mean diameter) is advantageous for fast adsorption kinetics and for UF retention (low ratio of PAC particles diameter to UF fibres diameter). Norit SA-UF PAC displays a positive net charge for $\mathrm{pH}$ values lower than 9.6, the point of zero charge [29]. Carbon was pre-wetted overnight before use.

\subsection{UF membrane and apparatus}

A hollow-fibre UF module (Aquasource) was used, with a hydrophilic cellulose acetate membrane $100 \mathrm{kDa}$ cut-off and $250 \mathrm{~L} /\left(\mathrm{h} \mathrm{m}^{2}\right.$ bar) hydraulic permeability (manufacturer data). The module (16 fibres, $1.1 \mathrm{~m}$ length and $0.93 \mathrm{~mm}$ internal diameter; $0.05 \mathrm{~m}^{2}$ total membrane area) was mounted in the lab system schematically illustrated in Fig. 1 and was operated in the cross-flow filtration mode using the inside-out configuration during the filtration cycles and the outside-in flow during backwashing.

\subsection{Ultrafiltration runs}

The membranes were first compacted with deionised water until achieving a steady permeate flux, at the pressure and cross- 


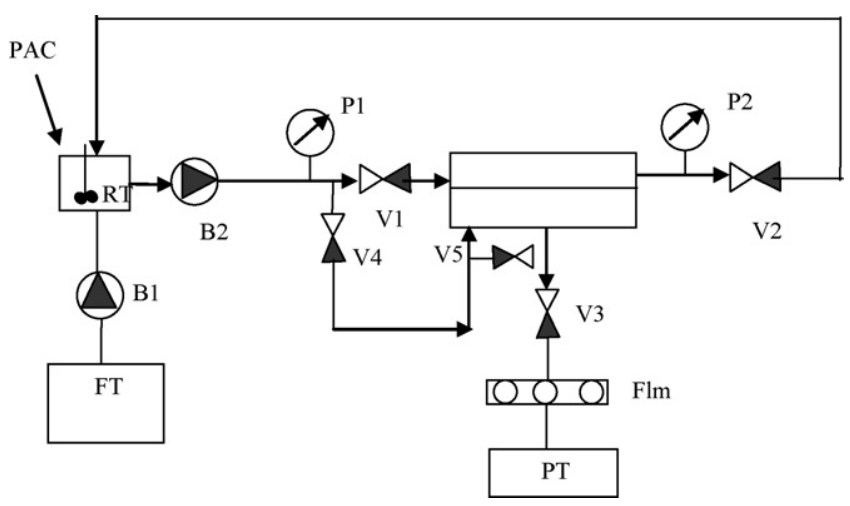

Fig. 1. Flow diagram of PAC/UF apparatus (FT-feed tank; RT-stirred recirculating tank; PT-permeate tank; Flm-flowmeter; P-manometers; B1-peristaltic pump; B2-positive displacement pump; V1, V4, V5-valves for backwashing; V2-concentrate valve; V3-permeate valve).

flow velocity to be used in the experiments. The UF runs (1-h cycles) were all performed at a constant permeate flow of $3.5 \mathrm{~L} / \mathrm{h}, 0.65 \mathrm{bar}$ initial transmembrane pressure and $0.5 \mathrm{~m} / \mathrm{s}$ cross-flow velocity. A feed glass tank fed the raw water to the recirculating tank through a peristaltic pump at a constant flow of $3.5 \mathrm{~L} / \mathrm{h}$ to balance the permeate outflow (Fig. 1). The positive displacement pump provided the necessary pressure and cross-flow velocity (a variable-frequency drive allowed the velocity in the hollow-fibres to be adjusted). The concentrate was conducted to the recirculating tank and blended with the additional feed water from the feed tank, whereas the permeate was continuously collected in a beaker until a $1 \mathrm{~L}$ sample was obtained. The cycles lasted $60 \mathrm{~min}$, i.e. four samples of permeate were always collected: three samples of $1 \mathrm{~L}$ each $(0-17 \mathrm{~min}$, 17-34 min, 34-51 $\mathrm{min}$ ) and the latter with ca. 0.5 L (51-60 min). Individual concentrations were determined and whenever necessary for data interpretation cycle-averaged values (0-60 min) were computed.

PAC was added directly into the continuously stirred recirculating tank (at $150 \mathrm{rpm}$ ) and was only disposed of at the end of the filtration cycle. Different water volumes in the recirculating tank were tested (to study different hydraulic retention times), as well as different PAC dosing procedures, i.e. the addition of the total PAC mass at the beginning of the filtration cycle (single-pulse dosing, PAC_1 $1 \times$ ) or the step addition of small portions of PAC throughout the filtration cycle (multi-pulse dosing, PAC_3 $\times$ : the first portion was added at the beginning of the cycle and the others after 15 and $30 \mathrm{~min}$ ).

After each filtration cycle, the membrane was backwashed (outside-in flow) during $1 \mathrm{~min}$ with a $5-\mathrm{mg} / \mathrm{L}\left(\right.$ as $\mathrm{Cl}_{2}$ ) sodium hypochlorite solution to inhibit the biological growth within the membrane module and the UF apparatus and flushed (inside-out flow) with deionised water for $3 \mathrm{~min}$.

\subsection{Adsorption kinetics}

For comparison purposes, an adsorption kinetic experiment was performed with the MC model solution $(2.5 \mathrm{mM}$ ionic strength,

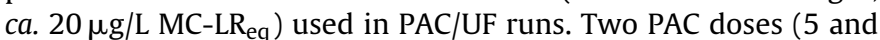
$10 \mathrm{mg} / \mathrm{L}$ ) and $1 \mathrm{~h}$ contact time (as in PAC/UF runs) were tested. The model solution was added to $250 \mathrm{~mL}$ bottles leaving a $20-\mathrm{mL}$ headspace. PAC was added, the bottles were sealed and stirred $\left(250 \mathrm{rpm}, 23^{\circ} \mathrm{C}\right)$ and samples were taken at predetermined time intervals over a 1 -h period. The samples were filtered through a Whatman GF/F glass microfibre filter and further processed for dissolved MC analysis.

\subsection{Analytical methods}

Samples were all analysed for pH (at $20^{\circ} \mathrm{C}$, using a WTW 340 $\mathrm{pH}$ meter), electrical conductivity (at $25^{\circ} \mathrm{C}$, with a Crison GLP 32 conductivity meter), turbidity (HACH $2100 \mathrm{~N}$ turbidimeter of high resolution, $0.001 \mathrm{NTU}$ ) and dissolved MC concentration. Samples from the experiments with microcystins and NOM (tannic and humic acids, and $M$. aeruginosa culture) were further analysed for UV absorbance at 215 and $254 \mathrm{~nm}$ (UV/VIS spectrophotometer Beckman DU 640B). A previous set of UV screening tests showed that in a mixture of tannic and humic acids $U_{215 \mathrm{~nm}}$ may be used as an indicator of tannic acid concentration whereas $U_{2} V_{254} \mathrm{~nm}$ is mostly related with the concentration of humic acids $[17,29]$. Samples with $M$. aeruginosa culture were also analysed for chlorophyll-a and intracellular MC concentration.

For chlorophyll-a analysis, $200 \mathrm{~mL}$ (feed) or $1 \mathrm{~L}$ (permeate) samples were filtered through GF/F filter paper and the chlorophylls were extracted using $10 \mathrm{~mL}$ acetone (90\%). The optical densities of the extracts were measured at 665 and $750 \mathrm{~nm}$ using a Beckman DU 640B UV/VIS spectrophotometer and chl-a concentration was computed from Lorenzen equations [32].

The analysis of microcystins followed the standard operation procedures developed by Meriluoto and Spoof $[28,33,34]$ with some adaptations. Extracellular microcystins were first isolated from cell-bound microcystins by sample filtration through a Whatman GF/C glass microfibre filter [28]. The dissolved fraction was concentrated by solid phase extraction (isolute C18 cartridges) and eluted with $5 \mathrm{~mL}$ methanol $(90 \%)$ containing $0.1 \%(\mathrm{v} / \mathrm{v})$ trifluoroacetic acid (further details in [15]) [33]. For intracellular MC analysis, the filters were freeze-thawed twice and kept in methanol $75 \%(\mathrm{v} / \mathrm{v})$ during $18-24 \mathrm{~h}$ at $4{ }^{\circ} \mathrm{C}$. The methanolic extracts of the dissolved and intracellular fractions were rotary evaporated $\left(50^{\circ} \mathrm{C}\right)$, resuspended in $500 \mu \mathrm{L}$ methanol $(75 \%)$, centrifuged $(10,000 \times g, 10 \mathrm{~min})$ and $150 \mu \mathrm{L}$ of the supernatant were transferred to HPLC vials for analysis. Microcystins were analysed by HPLC-PDA [34], using a Dionex Summit System with a C18 column (Merck Purospher STAR RP-18 endcapped, $3 \mu \mathrm{m}$ particles, LiChroCART $55 \times 4 \mathrm{~mm}$ ) and the overall concentration of the four variants was quantified as MC-LR eq.

\section{Results and discussion}

\subsection{Removal of microcystins by PAC/UF}

Several PAC/UF experiments were performed to investigate the $M C$ removal efficiency and to assess the influence of MC initial concentration and PAC dose, as well as PAC dosing procedure and hydraulic retention time on the recirculating tank. Fig. 2 presents the cycle-averaged concentrations of microcystins in the feed and permeate obtained with two feed concentration ranges (ca. $5 \mu \mathrm{g} / \mathrm{L}$

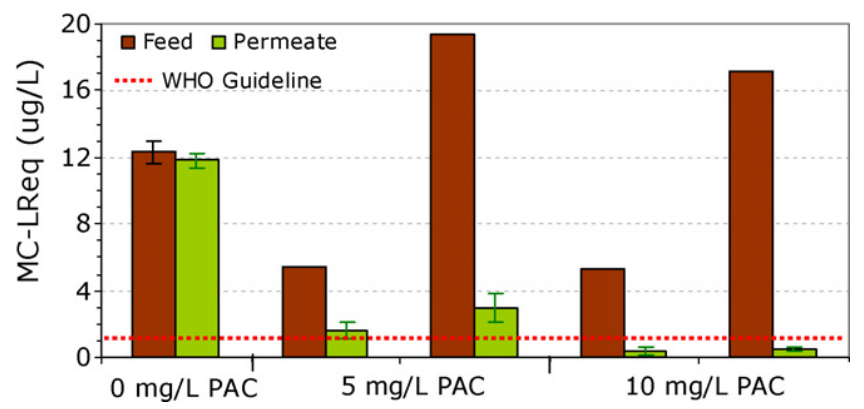

Fig. 2. Cycle-averaged concentration of microcystins in UF and PAC/UF permeate obtained with different feed concentrations and PAC doses (error bars represent standard deviations) 


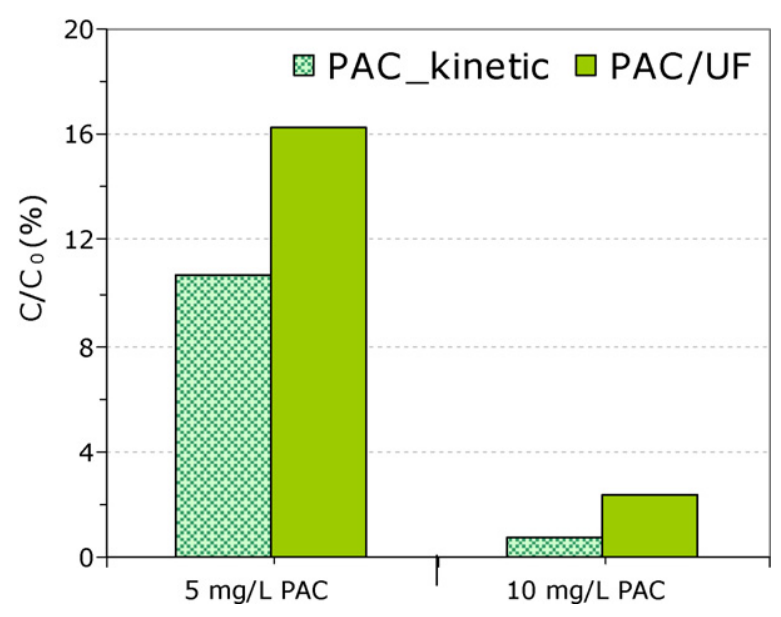

Fig. 3. Normalised concentration of microcystins after PAC/UF and PAC adsorption kinetic experiments performed in the same operating conditions $\left(17.1 \mu \mathrm{g} / \mathrm{L} \mathrm{MC}-\mathrm{LR}_{\mathrm{eq}}\right.$ feed concentration, two PAC doses and 1-h contact time).

MC-LR eq and 17-20 $\mu \mathrm{g} / \mathrm{L}$ MC-LR eq ) and two PAC doses (5 and $10 \mathrm{mg} / \mathrm{L}$, single-pulse dosing). For comparison purposes, data from an analogous run with no PAC addition are also shown (ca. $12 \mu \mathrm{g} / \mathrm{L}$ MC-LReq).

With no PAC addition, the concentration of microcystins in the feed and permeate were similar, which agrees with a low average adsorption (ca. $4 \%$ ) by the cellulose acetate membrane. While the same trend was found in the literature for the same hydrophilic membrane material [18] stronger adsorption was reported for polyethersulphone $[16,18]$ or polysulphone [35] membranes.

Fig. 2 shows the benefit of PAC on the MC removal. Regardless of the MC feed concentration range tested high rejections were always reached, and they increased with the feed concentration. Removal efficiencies were between $70 \%$ and $84 \%$ with $5 \mathrm{mg} / \mathrm{L} \mathrm{PAC}$ and 93-98\% with $10 \mathrm{mg} / \mathrm{LPAC}$, which are consistent with the values of Lee and Walker [18]. They obtained $c a$. $88 \%$ of MC-LR removal for $50 \mu \mathrm{g} / \mathrm{L}$ MC-LR feed concentration, $5 \mathrm{mg} / \mathrm{L}$ of a wood-based PAC, a cellulose acetate membrane (flat-sheet, $20 \mathrm{kDa}$ ) and a contact time of $1 \mathrm{~h}$. Despite the high rejections obtained, PAC doses of $10 \mathrm{mg} / \mathrm{L}$ or higher were necessary to ensure a permeate concentration below the WHO guideline-value ( $1 \mu \mathrm{g} / \mathrm{L}$ MC-LR).

Comparing PAC/UF (1-h cycle) with the 1-h adsorption kinetics performed with the same model solution and PAC doses (Fig. 3), it can be concluded that the former had a lower microcystins adsorption. As recently found by Ivancev-Tumbas et al. [36] and corroborated by Campinas [17], this feature is probably associated with a poor distribution of PAC in the UF module and/or with a less favourable hydrodynamic regimen for microcystins adsorption onto PAC and is therefore an aspect to improve in PAC/UF systems operated under cross-flow.

Two key-operating conditions of PAC/UF systems were investigated, namely the PAC dosing procedure and the hydraulic retention time. Experiments were performed with two different PAC dosing procedures, single-pulse dosing (PAC_1 $1 \times$ ) and multipulse dosing $\left(\mathrm{PAC}_{-} \mathrm{X} \times\right)$, and no differences were found between them in terms of the transmembrane pressure necessary to maintain the constant flow. Actually, no significant pressure drop was observed during every constant flow run performed: the pressure drop (0.01-0.13 bar, i.e. $2-18 \%$ of the initial transmembrane pressure) was often very low and quite similar to the value observed during the control experiment $(0.07$ bar), the UF run with the electrolyte solution $2.5 \mathrm{mM}$ ionic strength (without microcystins and PAC). Moreover, the fluctuations observed could not be explained by different PAC doses, PAC dosing procedures or MC feed concentrations.

Fig. 4 shows the concentration profile of microcystins permeating the membrane through the 1-h cycle (left) and the cycle-averaged permeate concentration (right) for both dosing procedures (error bars represent standard deviations).

When the PAC was single-pulse dosed (PAC_1 $1 \times$ ), the microcystins concentration in the UF permeate decreased with the running time and reached a minimum (after $0.5 \mathrm{~h}$ of filtration), and then increased until the end of the cycle, doubling the minimum. However, for multi-pulse PAC addition (PAC_ $3 \times$ ) maximum permeate concentration was observed at the beginning of the cycle and then the concentration decreased as the filtration proceeded (Fig. 4, left). These observations are consistent with the findings of Campos et al. [20-22], Snoeyink et al. [24] and Matsui et al. [26]. The PAC_1× and PAC $3 \times$ procedures resulted in identical cycle-averaged concentration of microcystins ( 2.9 and $3.2 \mu \mathrm{g} / \mathrm{L}$ respectively) but rather different standard deviations (Fig. 4, right). The multi-pulse PAC dosing yielded quite high standard deviations due to the high concentrations found before adding the second (15 min after starting the run) and the third ( $30 \mathrm{~min})$ portions of PAC. While some authors $[20-22,24]$ have concluded that the single-pulse dosing mode results in better permeate quality since all carbon particles have a retention time equal to the filtration time, others $[26,36]$ have found no benefits of such procedure when removing micropollutants from natural water, given the higher NOM competition. Analogous experiments in the presence of NOM competition are therefore recommended as future work.

The experiments performed with two different hydraulic retention times in the recirculating tank showed that in the studied range the increase of the hydraulic retention time negatively impacted the MC removal (from $80 \%$ with $34 \mathrm{~min}$ to $71 \%$ with $55 \mathrm{~min}$ ) although it had no significant effect on the concentration profile, particularly during the second half of the 1-h run (Fig. 5, left), nor
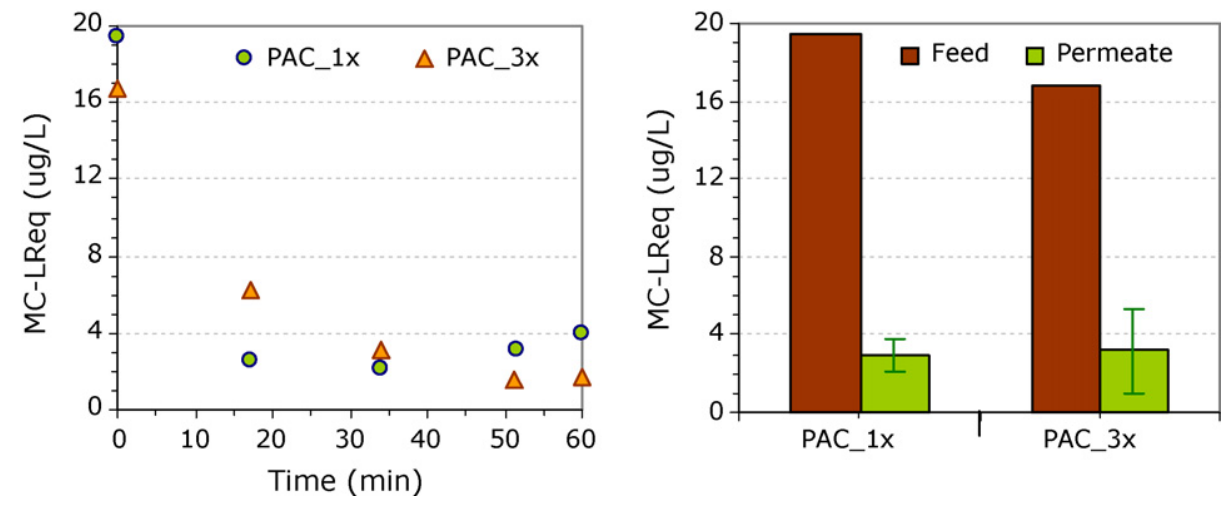

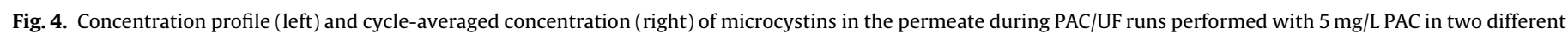
dosing procedures (error bars represent standard deviations). 

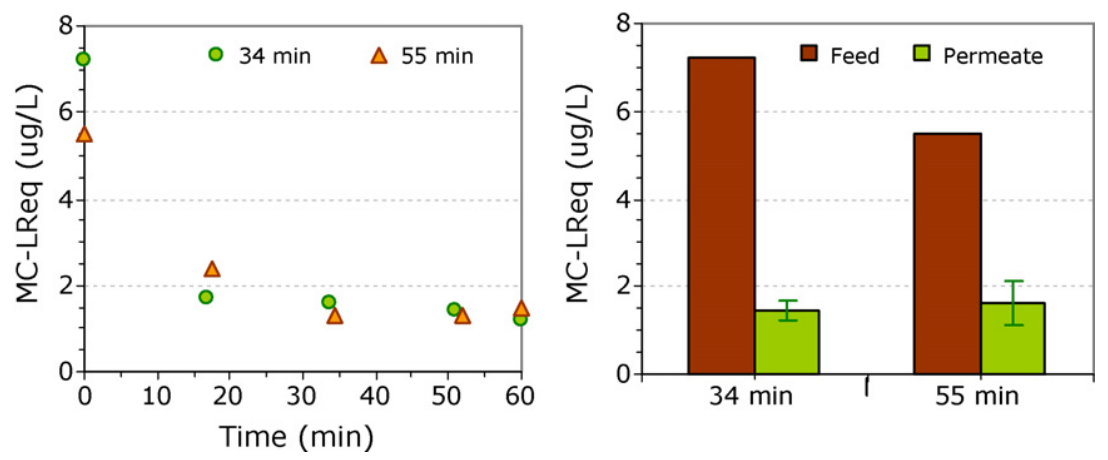

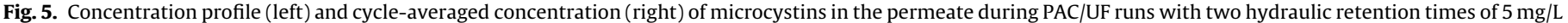
$\mathrm{PAC}$ in the recirculating tank (error bars represent standard deviations).

on the cycle-averaged concentration of microcystins in the perme-

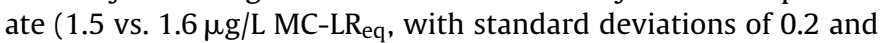
0.5; Fig. 5, right). Similar results were obtained by Campos et al. [21] based on model predictions. They concluded that a hydraulic retention time increase reduces the adsorption efficiency when feed water is considered as the initial solution in the reactor, as in the present study. However, when the permeate is partially recycled to the reactor (i.e. permeate is the initial solution) the model predicts no major impact of the hydraulic retention time on the adsorption efficiency.

\subsection{Effect of NOM on the removal of microcystins by PAC/UF}

A mixture of tannic and humic acids was used to investigate the NOM interference on the removal of microcystins by PAC/UF. Fig. 6 presents the cycle-averaged concentration of microcystins in the permeate of PAC/UF runs performed in the absence and in the presence of NOM surrogates for two microcystin feed concentration ranges (5-7 $\mu \mathrm{g} / \mathrm{L}$ MC-LR eq $_{\text {and }}$ 17-23 $\mu \mathrm{g} / \mathrm{L} \mathrm{MC-LR}_{\mathrm{eq}}$ ). Single-pulse dosing of 5, 10 and $15 \mathrm{mg} / \mathrm{L}$ PAC were studied.

For the lowest feed concentration $\left(5.3-7.4 \mu \mathrm{g} / \mathrm{L} \mathrm{MC}-\mathrm{LR}_{\mathrm{eq}}\right)$ and $10 \mathrm{mg} / \mathrm{L} \mathrm{PAC}$, the addition of $5 \mathrm{mg} / \mathrm{L}$ of NOM $(2.5 \mathrm{mg} / \mathrm{L}$ of each NOM surrogate) resulted in a significant increase in the cycle-averaged concentration of microcystins in the permeate (ca. $0.4-1.2 \mu \mathrm{g} / \mathrm{L}$ MC-LR eq Fig. 6, left), corresponding to a decrease in MC rejection from $93 \%$ to $82 \%$. Only augmenting PAC dose to $15 \mathrm{mg} / \mathrm{L}$ made it possible to achieve $90 \% \mathrm{MC}$ removal and a permeate concentration below the WHO guideline-value. When $2.5 \mathrm{mg} / \mathrm{L}$ of NOM was added (half the previous value; $1 \mathrm{mg} / \mathrm{L}$ humic acids and $1.5 \mathrm{mg} / \mathrm{L}$ tannic acid), there was no significant loss of microcystins removal and it was still possible to reach a permeate concentration below $1 \mu \mathrm{g} / \mathrm{L} \mathrm{MC-LR}$ eq with $10 \mathrm{mg} / \mathrm{L}$ PAC (Fig. 6, left). However, when
$5 \mathrm{mg} / \mathrm{L}$ of NOM was added to the higher range of MC feed concentration $\left(17.1-23.2 \mu \mathrm{g} / \mathrm{L} \mathrm{MC}_{\mathrm{L}} \mathrm{LR}_{\mathrm{eq}}\right)$ there was a substantial increase in the permeate concentration, from $0.4 \mu \mathrm{g} / \mathrm{L} \mathrm{MC-LR}$ eq (with no NOM addition) to $6.4 \mu \mathrm{g} / \mathrm{L} \mathrm{MC-LR}$ eq (Fig. 6, right), i.e. the MC removal decreased from $98 \%$ to $67 \%$. Increasing PAC dosage from 10 to $15 \mathrm{mg} / \mathrm{L}$ raised the MC removal from $67 \%$ to $81 \%$ but this was not enough to achieve a permeate quality fulfilling the WHO guidelinevalue. These results agree with the strong tannic acid-microcystins competition previously investigated [17], and are not distant from those obtained by Lee and Walker [18]. In PAC/UF experiments with a flat-sheet cellulose acetate membrane, these authors obtained a MC-LR rejection decrease of $20 \%$ (from $98 \%$ to $78 \%$ after $4 \mathrm{~h}$ of PAC contact time) when $5 \mathrm{mg} / \mathrm{L}$ of fulvic acid was added to a solution containing $50 \mu \mathrm{g} / \mathrm{L}$ MC-LR, and associated it with direct competition between the two similar size compounds.

Earlier work on competitive adsorption kinetics and isotherms between microcystins and NOM surrogates indicated that the purified Aldrich humic acids in the presence of background ionic strength are responsible for pore blocking mechanism, slowing down the rate of adsorption and reducing the PAC capacity for microcystins [17]. The same studies pointed to a more severe effect of tannic acid onto MC adsorption, with dominance of pore constriction mechanism and a contribution of direct competition for adsorption sites, especially at higher loadings.

Fig. 7 presents the UF and the PAC/UF removals of the competing NOM from solutions containing tannic and humic acids $(5 \mathrm{mg} / \mathrm{L}$ overall concentration) and two MC feed concentrations (6.7-7.4 and $19.5-23.2 \mu \mathrm{g} / \mathrm{L}$ MC-LR $\mathrm{Lq}_{\mathrm{eq}}$ ). With PAC addition, the $\mathrm{UV}_{215 \mathrm{~nm}}$ rejection increased $8 \%$ (for the high feed concentration (green bars) and $10 \mathrm{mg} / \mathrm{L} \mathrm{PAC}$ ) to $18 \%$ (for the low feed concentration (orange bars) and $15 \mathrm{mg} / \mathrm{L}$ PAC). The $\mathrm{UV}_{254 \mathrm{~nm}}$ rejection increased $8 \%$ (for both feed concentrations and $10 \mathrm{mg} / \mathrm{L} \mathrm{PAC}$ ) to $14 \%$ (with
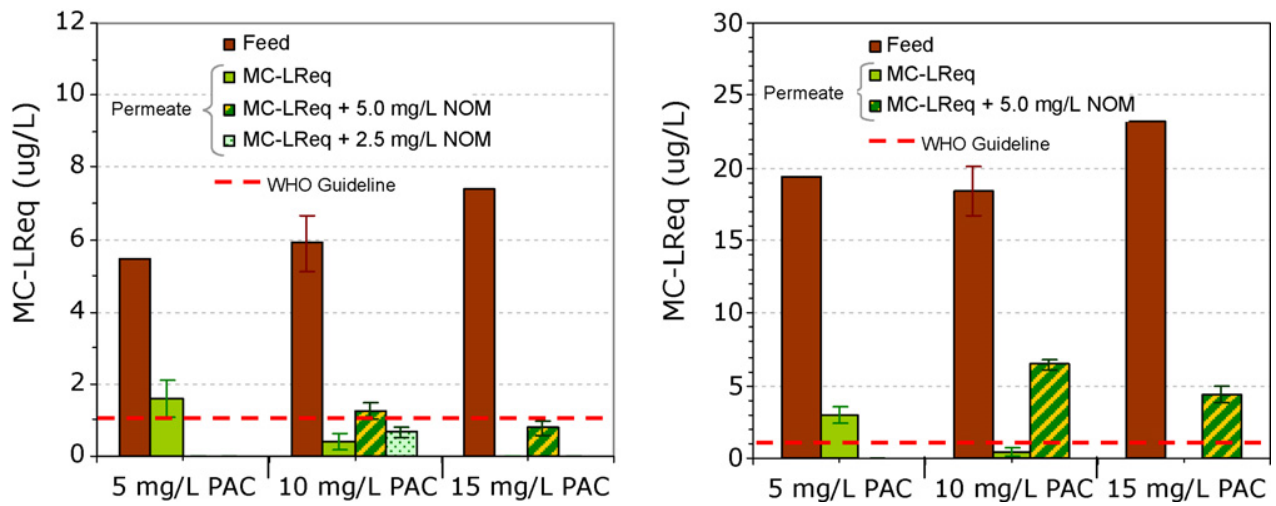

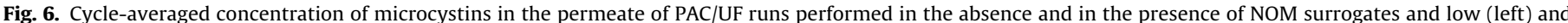
high (right) MC feed concentration (error bars represent standard deviations). 


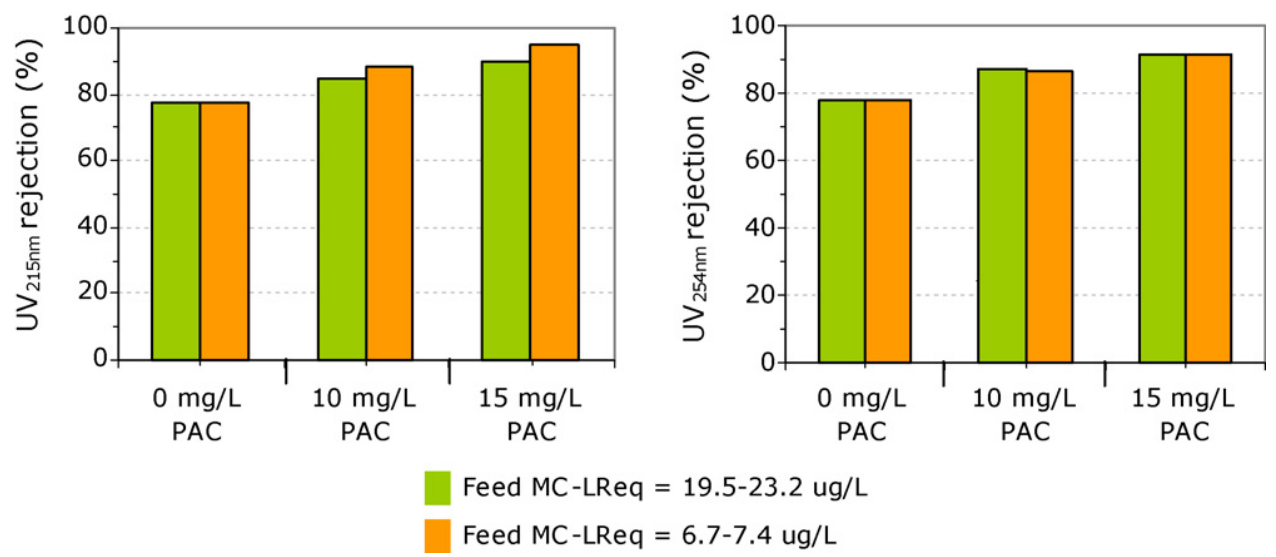

Fig. 7. UV rejections $\left(\mathrm{UV}_{215 \mathrm{~nm}}\right.$, left; $\mathrm{UV}_{254 \mathrm{~nm}}$, right) by PAC/UF with $5 \mathrm{mg} / \mathrm{L}$ NOM model solutions containing microcystins.

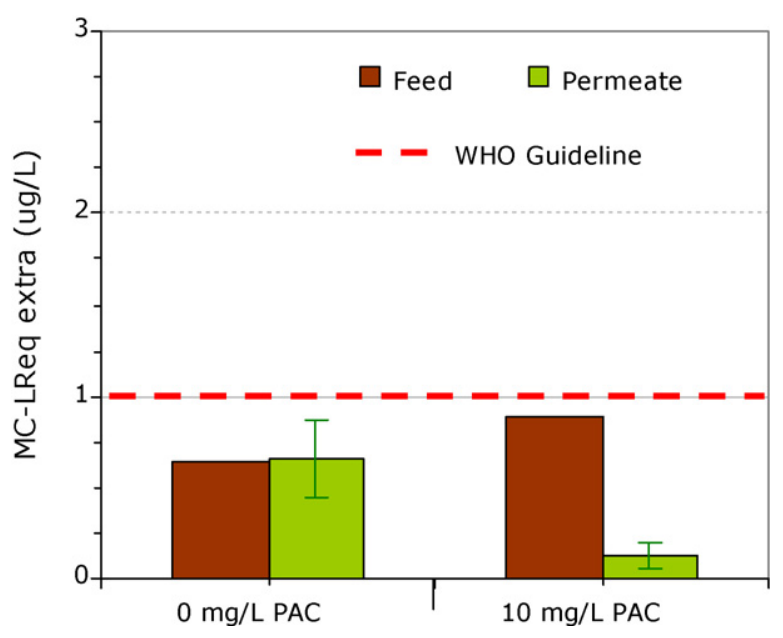

Fig. 8. Cycle-averaged concentration of microcystins in the permeate of UF and PAC/UF runs with $M$. aeruginosa suspension (2.1-2.3 $\mu \mathrm{g} / \mathrm{L} \mathrm{MC}^{\mathrm{L}} \mathrm{LR}_{\mathrm{eq}}$ (extra + intra), 0.4-0.6 extra/intra ratio; error bars represent standard deviations).

$15 \mathrm{mg} / \mathrm{L}$ PAC), comparatively to UF alone. The lower MC feed concentration resulted in higher $\mathrm{UV}_{215 \mathrm{~nm}}$ removals but no differences were observed at $254 \mathrm{~nm}$ (mostly related to humic acids), which is probably an indicator of higher removal of tannic acid. Earlier experiments pointed to an identical adsorption path between microcystins and tannic acid, where they are both affected [17].

M. aeruginosa suspension 2 months old (in the late-exponential growth phase confirmed by chlorophyll-a content, turbidity, extraand intracellular MC concentration and extra/intra MC ratio) was also investigated. The $M$. aeruginosa suspension contained cells ( $c a$. $20 \mu \mathrm{g} / \mathrm{L}$ chl-a), extra- and intracellular microcystins ( $2.3 \mu \mathrm{g} / \mathrm{L} \mathrm{MC}$ $\mathrm{LR}_{\mathrm{eq}}$ (extra + intra) and 0.4-0.6 extra/intra ratio) and algal organic matter.

Both UF and PAC/UF achieved an absolute removal of $M$. aeruginosa single cells, yielding a permeate with turbidity values below 0.1 NTU and with no chlorophyll-a, which indicates that intracellular microcystins were also removed. Fig. 8 compares the cycle-averaged concentration of dissolved microcystins in the permeate of UF ( $0 \mathrm{mg} / \mathrm{L}$ PAC) and PAC/UF ( $10 \mathrm{mg} / \mathrm{L}$ PAC) experiments.

The feed and permeate water of UF had similar concentration of dissolved microcystins ( 0.63 and $0.66 \mu \mathrm{g} / \mathrm{L}$ MC-LR $\mathrm{R}_{\mathrm{eq}}$, respectively). In recent trials, Campinas [17] concluded that UF may cause cell damage with subsequent release of microcystins to water, especially from older cells. However, in those experiments the permeate quality was never deteriorated since the microcystin rejection also increased with cell ageing, probably associated with the greater content in segregated AOM (mucopolysaccharides) and protein lysed organic matter. The data in Fig. 8 show that PAC/UF substantially improved the permeate quality, removing $86 \%$ of the dissolved microcystins (or more in the case of cell lysis occurrence), and producing a permeate with a very low cycle-averaged concentration $(<0.13 \mu \mathrm{g} / \mathrm{L}$ MC-LR eq $)$.

\section{Conclusions}

The removal of microcystins by a PAC/UF hybrid process was investigated, focusing on aspects such as PAC dose, MC feed concentration, specific operating conditions (PAC dosing procedure and hydraulic retention time on the recirculating tank) and NOM interference (humic acids, tannic acid and $M$. aeruginosa culture (cells and $\mathrm{AOM})$ ).

In the absence of background NOM, PAC/UF achieved 93-98\% $\mathrm{MC}$ removal and a permeate concentration below the WHO drinking water guideline-value ( $1 \mu \mathrm{g} / \mathrm{L}$ MC-LR) with $10 \mathrm{mg} / \mathrm{L}$ of PAC and for a feed concentration up to $c a .20 \mu \mathrm{g} / \mathrm{L}_{\mathrm{MC}} \mathrm{M}-\mathrm{LR}_{\mathrm{eq}}$. Hydrodynamic limitations were detected on PAC/UF operated under cross-flow mode, an aspect to improve in those systems.

The single-pulse PAC dosing at the beginning of the UF-cycle and the multi-pulse PAC addition throughout the filtration cycle resulted in very different MC concentration profiles although in identical cycle-averaged MC concentration in the permeate (with minor advantage for single-pulse dosing). No differences were also found between these two dosing procedures in terms of transmembrane pressure necessary to maintain the constant flow. An increase of the hydraulic retention time from 34 to 55 min negatively impacted the MC removal from $80 \%$ to $71 \%$.

The PAC dose required was mostly affected by NOM type and concentration, and by microcystin feed concentration. For low concentrations of microcystins (ca. $5 \mu \mathrm{g} / \mathrm{L}$ MC-LR eq $) 10 \mathrm{mg} / \mathrm{L}$ of PAC effectively controlled the microcystins in a model water with $M$. aeruginosa culture or with $2.5 \mathrm{mg} / \mathrm{L}$ of NOM surrogates (a mixture of tannic and humic acids) whereas a PAC dose of $15 \mathrm{mg} / \mathrm{L}$ was necessary when the NOM surrogate concentration doubled. For high concentrations of microcystins ( $c a .20 \mu \mathrm{g} / \mathrm{L}$ MC-LR eq $)$ and NOM $(5 \mathrm{mg} / \mathrm{L}) 15 \mathrm{mg} / \mathrm{L}$ of PAC were unable to achieve the WHO guideline-value.

Depending on the microcystin feed concentration, as well as on the type and concentration of the competing compounds, the PAC doses may have to be adjusted to overcome the NOM presence. Strategies to control the NOM competition and the membrane fouling include pre-treatment steps, increasing PAC doses (by $50 \%$, $100 \%$, or higher) and/or PAC contact time, adjusting PAC porous structure and/or particle size. 


\section{Acknowledgments}

The authors would like to thank the Portuguese Science and Technology Foundation, for providing a Ph.D. scholarship to Margarida Campinas (BD/10356/2002). Special thanks are also addressed to Águas do Algarve, SA (Portugal), for partially funding this project.

\section{References}

[1] K. Sivonen, G. Jones, Cyanobacterial toxins, in: I. Chorus, J. Bartram (Eds.), Toxic Cyanobacteria in Water: A Guide to Their Public Health Consequences, Monitoring and Management, 1st edition, WHO, E \& SPON, London, 1999.

[2] A. Keijola, K. Himberg, A. Esala, K. Sivonen, L. Hiisvirta, Toxicity Asses.: An Int. J. 3 (1988) 643-656.

[3] K. Himberg, A. Keijola, L. Hiisvirta, H. Pyysalo, K. Sivonen, Water Res. 23 (8) (1989) 979-984.

[4] L. Lawton, P. Robertson, Chem. Soc. Rev. 28 (1999) 217-224.

[5] J. Rositano, G. Newcombe, B. Nicholson, P. Sztajnbok, Water Res. 35 (1) (2001) 23-32.

[6] J. Acero, E. Rodriguez, J. Meriluoto, Water Res. 39 (8) (2005) 1628-1638.

[7] E. Rodríguez, G. Onstad, T. Kull, J. Metcalf, J. Acero, U. Gunten, Water Res. 41 (2007) 3381-3393.

[8] G. Hervé, U. von Gunten, Water Res. 36 (1) (2002) 65-74.

[9] W.J. Huang, Y.Y. Tsai, C. Chu, Subst. Environ. Eng. 38 (12) (2003) 2919-2931.

[10] U. Von Gunten, Water Sci. Technol. 55 (12) (2007) 25-29.

[11] S. Hoeger, D. Dietrich, B. Hitzfeld, Environ. Health Perspect. 110 (11) (2002) 1127-1132.

[12] G. Newcombe, B. Nicholson, J. Water Sci. Res. Technol.: Aqua 53 (4) (2004) 227-239.

[13] R. Daly, L. Ho, J. Brookes, Environ. Sci. Technol. 41 (2007) 4447-4453.

[14] M. Ribau Teixeira, M.J. Rosa, Sep. Purif. Technol. 46 (2005) 192-201.

[15] M. Ribau Teixeira, M.J. Rosa, Water Res. 40 (2006) 2837-2846.

[16] A. Gijsbertsen-Abrahamse, W. Schmidt, I. Chorus, S. Heijman, J. Membr. Sci. 276 (2006) 252-259.

[17] M. Campinas, Removal of cyanobacteria and cyanotoxins from drinking water by powdered activated carbon adsorption/ultrafiltration, Ph.D. Thesis in Envi- ronmental Sciences and Technologies, Algarve University, Faro, Portugal, 2009.

[18] J. Lee, H. Walker, Environ. Sci. Technol. 40 (2006) 7336-7342.

[19] S. Adham, V. Snoeyink, M. Clark, J.-L. Bersillon, J. Am. Water Works Assoc. 12 (1991) 81-91.

[20] C. Campos, B. Mariñas, V. Snoeyink, I. Baudin, J. Laîné, Desalination 117 (1998) 265-271.

[21] C. Campos, B. Mariñas, V. Snoeyink, I. Baudin, J. Laîné, J. Environ. Eng. 126 (2) (2000) 104-111.

[22] C. Campos, L. Schimmoller, B. Mariñas, V. Snoeyink, I. Baudin, J. Laîné, J. Am. Water Works Assoc. 92 (8) (2000) 69-83.

[23] C. Campos, I. Baudin, J. Laîné, Water Sci. Technol.: Water Supply 1 (5/6) (2001) 13-19.

[24] V. Snoeyink, C. Campos, B. Mariñas, Water Sci. Technol. 42 (12) (2000) 1-10.

[25] Y. Matsui, A. Yuasa, K. Ariga, Water Res. 35 (2) (2001) 455-463.

[26] Y. Matsui, A. Yuasa, F. Colas, Water Sci. Technol.: Water Supply 1 (5/6) (2001) 39-47.

[27] R.Y. Stanier, R. Kunisawa, M. Mandel, G. Cohen-Bazire, Bacteriol. Rev. 35 (2) (1971) 171-205.

[28] J. Meriluoto, L. Spoof, SOP: extraction of microcystins in biomass filtered on glass-fibre filters or in freeze-dried cyanobacterial biomass, in: J. Meriluoto G. Codd (Eds.), Toxic Cyanobacterial Monitoring and Cyanotoxin Analysis, Abo Akademi University Press, Finland, 2005.

[29] M. Campinas, M.J. Rosa, J. Colloid Interface Sci. 299 (2006) 520-529.

[30] E. Yamada, K. Doi, K. Okano, Y. Fuse, Anal. Sci. 16 (2) (2000) 125-129.

[31] H. Yamamoto, H. Liljestrand, Y. Shimizu, M. Morita, Environ. Sci. Technol. 37 (12) (2003) 2646-2657.

[32] C.J. Lorenzen, Limnol. Oceanogr. 12 (2) (1967) 343-346.

[33] J. Meriluoto, L. Spoof, SOP: solid phase extraction of microcystin in water samples, in: J. Meriluoto, G. Codd (Eds.), Toxic Cyanobacterial Monitoring and Cyanotoxin Analysis, Abo Akademi University Press, Finland, 2005.

[34] J. Meriluoto, L. Spoof, SOP: analysis of microcystins by high-performance liquid chromatography with photodiode-array detection, in: J. Meriluoto, G. Codd (Eds.), Toxic Cyanobacterial Monitoring and Cyanotoxin Analysis, Abo Akadem University Press, Finland, 2005.

[35] C. Chow, S. Panglish, J. House, M. Drikas, M. Burch, R. Gimbel, J. Water Sci. Res. Technol.: Aqua 46 (6) (1997) 324-334.

[36] I. Ivancev-Tumbas, R. Hobby, B. Küchle, S. Panglisch, R. Gimbel, Water Res. 42 (2008) 4117-4124. 